\title{
Communicative Action and the Other of Justice
}

\author{
KOME - An International Journal of Pure \\ Communication Inquiry \\ Volume 3 Issue 2, p. 27-43. \\ (C) The Author(s) 2015 \\ Reprints and Permission: \\ kome@komejournal.com \\ Published by the Hungarian Communication \\ Studies Association \\ DOI: 10.17646/KOME.2015.23
}

\section{Domonkos Sik}

Eötvös Loránd University, Department of History of Social Theory, Hungary

\begin{abstract}
Communicative action is the coordination mechanism of social actions. However, being a social action itself, it needs coordination in case of obstruction. Such obstruction is especially frequent in late modern constellation burdened with the "individualization of life forms" (Beck) and the "dissolution of a mutual ground" (Lash). I call the mechanism capable of overcoming such obstruction the "coordination of action coordination." In the following essay, this notion is elaborated. Firstly, on the level of formal pragmatics, situations that implicate action coordination are specified. Secondly, the coordinating mechanism of action coordination is elaborated in the frames of the Habermasian theory as the harmonization of different concepts of justice underlying action coordination. Thirdly, a paradoxical aspect of this solution is introduced, which originates from the strict linguistic-intentional character of Habermas's theory. Fourthly, based on Levinas's pre-intentional ethical phenomenology, an alternative description of the coordination of action coordination is elaborated. Finally, the broader theoretical consequences of the new solution are detailed.
\end{abstract}

Keywords: communicative action, Habermas, Levinas

\section{Introduction}

In one of his recent essays, Honneth evaluates the different postmodern philosophical projects from the perspective of the Habermasian discourse ethics (2007). He argues that the attempts of authors like Lyotard or Stephen K. White to overcome the limitedness of Kantian moral philosophy by leaving behind the questions of justice are unsuccessful. As these attempts can be reformulated within discourse ethics, which is a rephrasing of the Kantian ideas, they cannot reach their goal. However, other postmodern authors, like Levinas or Derrida, provide new perspectives beyond the horizon of Kantian moral philosophy. Their 
most important ethical notion, human care (Fürsorge), refers to an alternative source of morality, "the other" of the cognitive, universalistic notion of justice.

On the foundational level of the Habermasian communication theory and social philosophy lies the concept of discourse ethics. The key notion of Habermas's thinking, communicative action, is supplemented by a theory of justice, as the willingness to pursue an undistorted discourse depends on the actors' moral perspective. That is where Honneth's idea becomes important: if an alternative concept of morality can be introduced based on the notion of care (instead of justice), it has consequences for all communication theories rooted in a moral philosophy based on the notion of justice. All of them - including the whole Habermasian theory - could be revised from the new moral perspective as questions arise: What is the relation of the two types of morality (complementary, ambiguous, or conflicting)? How and in what situations do they interfere?

In the following essay, an attempt will be made for such a revision by introducing a phenomenon wherein the two types of morality complement each other. In The Theory of Communicative Action, Habermas elaborates a synthesis of a phenomenological and a system theoretic answer to the question of how social action is possible. While on the phenomenological level, the coordination of social action is explained with the harmonization of the actors' meanings, on the system theoretic level, it is explained with the non-linguistic mediums. According to Habermas, mutual understanding is a phenomenological presupposition of social actions. It is basically guaranteed by a common lifeworld of the actors, which provides the same unreflected interpretation of a situation. In situations where this common horizon is not pre-given, an explicit effort is needed to create it. This effort is referred to as communicative action, a process of coming to an agreement concerning the interpretation of the situation. In this sense, communicative action is the mechanism of action coordination, complementary of the lifeworld. Simultaneously, communicative action is not just the coordinating mechanism of social actions; it is a social action on its own as well. Therefore, questions concerning its coordination mechanism may legitimately be posed. How can the situation be described when action coordination is obstructed? And how can the mechanism be described that may solve this disturbance?

In the late modern constellation, these questions are becoming especially important, as the life paths individualize (Beck 1992) and "difference" becomes the ground (Lash 1999). In this constellation, not only the mutual lifeworld dissolves but the frames of those communicative processes are also weakened, which is supposed to recreate a mutual horizon. Despite these diagnoses, Habermas himself did not pose questions concerning the obstruction of action coordination. Therefore, the following attempt will be made to fill this gap. I will argue that these questions lead to the fundamental problems of meaning formulation - to the problem of "coordinating action coordination" - and may be answered only by leaving the Habermasian concept of morality based solely on justice and stepping back to the alternative source of morality carefully analyzed by Levinas.

In what follows, firstly, the problem of coordinating action coordination will be elaborated by briefly evoking Habermas's formal pragmatics. The problem will be introduced as the interruption of a series of speech acts constituting the communicative action and resulting from the discrepancies of the actors' concepts of justice defining the order of speech acts. Secondly, a harmonization process will be shortly outlined solely within the Habermasian frames. To describe the mechanism that coordinates action coordination and to elaborate a linguistic-intentional solution, the dynamics of moral development (discussed in the discourse ethics) are recalled. Accordingly, the coordination of action coordination may be introduced as a harmonization of the underlying concepts of justice. Thirdly, the limits of the linguistic-intentional solution will be pointed out, and a new approach potentially transcending them will be outlined. At this point, Levinas's ideas on the moral obligation 
invoked by the experience of the Face of the Other will be applied in order to describe a mechanism capable of reestablishing the moral basis of speech acts. Finally, in the concluding remarks, the broader theoretical consequences of this solution will be outlined. ${ }^{1}$

\section{The problem of coordinating action coordination}

The Theory of Communicative Action is grounded on the level of formal pragmatics, that is, on the level of a theory of mutual understanding. Habermas describes the conditions of mutual understanding by reconstructing the potential sequence of speech acts. The reconstruction results in a script, which might end either in the suspension of the communication or in the mutual acceptance of the validity claims of a speech act, that is mutual understanding.

Table 1: Undistorted sequence of speech acts

\begin{tabular}{|c|c|c|}
\hline rounds/ speakers & speaker "A" & speaker "B" \\
\hline 1. round & $\begin{array}{l}\text { formulates speech act "p" } \rightarrow \\
\text { raises validity claims (what } \\
\text { she is saying is true and } \\
\text { right and she is truthful) }\end{array}$ & \\
\hline \multirow[t]{2}{*}{ 2. round } & & $\begin{array}{l}\text { either accepts the validity } \\
\text { claims of "p" } \rightarrow \text { mutual } \\
\text { understanding (successful } \\
\text { ending of communication) }\end{array}$ \\
\hline & & $\begin{array}{l}\text { or refuses one of the validity } \\
\text { claims of "p" } \rightarrow \text { formulates } \\
\text { speech act "q" }\end{array}$ \\
\hline \multirow[t]{2}{*}{ 3. round } & $\begin{array}{l}\text { either accepts the validity } \\
\text { claims of "q" } \rightarrow \text { revokes "p" } \\
\rightarrow \text { mutual understanding } \\
\text { (successful ending of } \\
\text { communication) }\end{array}$ & \\
\hline & $\begin{array}{l}\text { or refuses one of the validity } \\
\text { claims of "q" } \rightarrow \text { formulates } \\
\text { speech act "r" }\end{array}$ & \\
\hline \multirow[t]{2}{*}{ 4. round } & & $\begin{array}{l}\text { either accepts the validity } \\
\text { claims of "r" } \rightarrow \text { revokes "q" } \\
\rightarrow \text { mutual understanding } \\
\text { (successful ending of } \\
\text { communication) }\end{array}$ \\
\hline & & $\begin{array}{l}\text { or refuses one of the validity } \\
\text { claims of "r" } \rightarrow \text { formulates } \\
\text { speech act "s" }\end{array}$ \\
\hline 5. round & etc. & \\
\hline
\end{tabular}

Table 1 shows such a script: every time a speech act is formulated, three validity claims are raised, which claims can be accepted (resulting in the new consensus) or refused (resulting in a new speech act that raises three validity claims that can be accepted or refused etc.). In case of undistorted communicative action this sequence is continued until a speech act is mutually accepted and a common interpretation of the situation is born. However, this sequence may be interrupted in at least two ways. Firstly, one of the speakers may willingly shift from the action oriented to mutual understanding to the strategic use of language. The latter may take the shape of open violence (threat) or hidden violence (manipulation, lie). In these cases

\footnotetext{
${ }^{1}$ The main argument of the article concerning the synthesis of Habermas' and Levinas' concepts has been elaborated in a socialization theoretical context in my book A modernizáció ingája (Sik 2012). This time however, the problem of coordinating action coordination is analyzed from a communication and social theoretical perspective.
} 
action coordination is blocked due to reasons external to the communication (i.e. the intention of an actor) so the process may be restored by eliminating the external reason.

The second, less obvious case is connected to the limited rationality of the lifeworld, to dogmatic meanings. A meaning is called dogmatic if it is not open to critical evaluation, that is, if it is sustained without proper justification. Dogmatic meanings are originally acquired through distorted communicative processes and as such, they can not be justified with rational arguments. ${ }^{2}$ At this point it is important to emphasize that according to Habermas' theory (and to the late Wittgenstein's heritage) meanings are not closed units of sense that can be either dogmatic or open to criticism per se. Instead they are born and exist only in interactions, therefore they are valid only for the actors and only during the given action situation. Furthermore, in addition to knowing the rules of its use, knowing a meaning includes knowing its justification as well. ${ }^{3}$ Accordingly in this theoretical setting dogmatism is neither the characteristic of the meaning itself (because meanings are embedded in situations) nor that of the actor (because meanings are created in interactions not by single subjects), but belongs to the interaction it is born in. Dogmatism is a characteristic of the process within which the meanings are formulated, i.e. it is a characteristic of the sequence of speech acts. It shows itself by causing a rupture in the sequence: it occurs when one of the speakers holds on to her speech act without being able to justify it with rational arguments. In this case the other speaker is hindered in continuing the series because neither was her speech act accepted, nor has she anything to accept or refuse.

Table 2: Full sequence of speech acts

\begin{tabular}{|c|c|c|}
\hline rounds/ speakers & speaker "A" & speaker "B" \\
\hline 1. round & $\begin{array}{l}\text { formulates speech act "p" } \rightarrow \\
\text { raises validity claims (what } \\
\text { she is saying is true and } \\
\text { right and she is truthful) }\end{array}$ & \\
\hline \multirow[t]{2}{*}{ 2. round } & & $\begin{array}{l}\text { either accepts the validity } \\
\text { claims of "p" } \rightarrow \text { mutual } \\
\text { understanding (successful } \\
\text { ending of communication) }\end{array}$ \\
\hline & & $\begin{array}{l}\text { or refuses one of the validity } \\
\text { claims of "p" } \rightarrow \text { formulates } \\
\text { speech act "q" }\end{array}$ \\
\hline \multirow[t]{3}{*}{ 3. round } & $\begin{array}{l}\text { either accepts the validity } \\
\text { claims of "q" } \rightarrow \text { revokes "p" } \\
\rightarrow \text { mutual understanding } \\
\text { (successful ending of } \\
\text { communication) }\end{array}$ & \\
\hline & $\begin{array}{l}\text { or refuses one of the validity } \\
\text { claims of "q" } \rightarrow \text { formulates } \\
\text { speech act "r" }\end{array}$ & \\
\hline & $\begin{array}{l}\text { or changes to open or hidden } \\
\text { violence } \rightarrow \text { willing } \\
\text { interruption of } \\
\text { communicative action } \rightarrow \\
\text { unsuccessful ending of }\end{array}$ & \\
\hline
\end{tabular}

\footnotetext{
${ }^{2}$ Communicative action is not only a mechanism of action coordination, but it is the mechanism of reproducing the different aspects of lifeworld as well (that is socialization, cultural reproduction and social integration). Hence the distortion of communicative action leaves its mark on these processes potentially causing psychopathologies, loss of meaning and anomie (Habermas 1987: 143). Habermas discusses the problem of dogmatic meanings extensively in his essay Reflections on Communicative Pathology (1998). There he argues that the occurrence of this phenomenon is most probable in families characterized by asymmetric powerstructure, by the impossibility of open discussion of conflicts.

${ }^{3}$ This is a key idea of The Theory of Communicative Action, because Habermas establishes his whole theory of rationality on the basis of an accountable actor capable and willing to justify her actions (1984: 22). Only an actor capable and willing to justify her motives can participate in the above sketched sequence of speech acts.
} 


\begin{tabular}{|l|l|l|}
\hline \multirow{2}{*}{} & communication & \multirow{2}{*}{} \\
\cline { 2 - 3 } & $\begin{array}{l}\text { or refuses "q" without } \\
\text { justifying "p" (i.e. without } \\
\text { formulating speech act "r") } \\
\rightarrow \text { unwilling interruption of } \\
\text { communicative action }\end{array}$ & \\
\hline 4. round & & $? ? ?$ \\
\hline
\end{tabular}

Table 2 shows all possible variations of the sequence including the two types of distortion. As mentioned before, the willing interruption of communicative action may be corrected by eliminating its cause external to the communication (i.e. by changing the intention of the actor). However, in case of unintended interruption, the correction is far more complicated. In this case the cause of the interruption is not external to the communication. The speakers are probably willing to continue their action oriented to mutual understanding, when they face the unexpected disturbance of communication: a speech act whose validity claim is not accepted, and which is in the same time sustained but unjustified. It is important to see, that at this point of interruption the pragmatic order of communication is damaged: sustaining without justifying a speech act is a pragmatic paradox, a violation of the very rules of communication. This violation mirrors a dissent concerning the fundamental structure underlying the order of speech acts. It expresses that the speaker does not perceive the other as someone to whom she is obliged either to justify or to give up her validity claim. Consequently, it may be stated that in fact it is an attribute of the actors' relationship that is responsible for the interruption. As the relationship of the speakers is an inherent feature of the interaction, the cause of the interruption is internal to communication. As such, unlike in case of willing interruption of communicative action, the unintended interruption may be corrected only within the frames of communication, by special interactions. In this sense, unlike in the first case, the unintended interruption does not necessarily lead to the ending of the communication; it may be successfully treated within its frames.

To describe the exact nature of such a correcting mechanism, two questions have to be answered. Firstly the nature of the fundamental structure underlying the order of speech acts has to be specified. Secondly the mechanism capable of reestablishing communication has to be outlined. In the following section I will elaborate an answer to these questions, leaning on Habermas' early reception of psychoanalysis and later ideas on discourse ethics.

\section{The coordination mechanism of action coordination}

Even if he does not explicitly analyze the problem of coordinating action coordination, in his early major book, Knowledge and Human Interest, Habermas discusses a structurally analogous problem (1971). In this book, he attempts to differentiate the critical social theory from other social sciences by specifying its underlying interest, the "emancipatory interest." To describe the emancipatory interest, Habermas carefully analyzes the interest underlying psychoanalytic therapy. In the therapeutic situation, the therapist and patient share the same goal of critically reflecting on the patient's meanings and reformulating the ones being born in distorted communication. Therefore, psychoanalytic therapy serves not only as a model of identifying the restrained elements of the lifeworld, the results of distorted communicative socialization, but also as a model of overcoming the dogmatism by a re-socialization process. ${ }^{4}$ This re-socialization process is basically an undistorted communicative action

\footnotetext{
4 This mixing of praxis and theory was criticized by many commentators. Thomas McCarthy mentions for example that the synthesis of the basically theoretical-epistemological ideas of Kant and Hegel and the mainly
} 
serving the purpose of reevaluating the meanings by the standards of communicative rationality. Those meanings that were originally formulated in distorted communication are disapproved; those that were formulated in undistorted communication are maintained. ${ }^{5}$

Albeit Habermas used psychoanalysis as an example of the praxis of critical social science, its application may be fruitful for our purposes as well. In my opinion, the problem of coordinating action coordination may be best approached in comparison with the psychoanalytic therapy. Therapy may be defined as a special social action situation wherein the de-dogmatization of certain meanings occurs. During therapy, the roles of the therapist and patient are mutually accepted, establishing a mutually accepted order of speech acts. The patient wants to overcome her dogmatic meanings, and to do so, she follows the instructions of the therapist. Accordingly, their relationship can be characterized as a legitimate authority (in the Weberian sense) that is a mutually recognized order. Based on her authority, the therapist can motivate the patient to face her meanings and judge them on the basis of their justifiability, even if it is difficult. At this point, the similarity and the difference between the therapy and the coordination of action coordination may be phrased. Both processes aim to open up the dogmatic lifeworld to criticism. In the first case, however, the frames of the emancipatory communication are well defined and mutually accepted, contrary to the second case in which these frames are absent. Therefore, the main question arising in processes of coordination of action coordination is as follows: How do we establish a legitimate order wherein the speaker has the mutually recognized right to motivate her partner either to resign or justify her speech acts?

Habermas discusses the question of the order underlying the speech acts in his essay Moral Consciousness and Communicative Action (1990). Therein he reconstructs the link between the Kohlbergian concept of moral development, the social perspectives, and the types of action coordination. Kohlberg identifies six levels of moral development, each characterized by a more general concept of justice. ${ }^{6}$ The concepts of justice determine the moral obligations of the subject. Moral obligations define, among others, the perception of the other and hereby the order of the speech acts. They determine to whom the subject is supposed to be obliged to either justify or resign her validity claims. Accordingly, the key to the problem of coordinating action coordination lies on the level of moral development. As described above, situations that require coordination of action coordination can be defined by an actor who does not recognize the other as someone to whom she is obliged to justify or resign her validity claims. According to Moral Consciousness and Communicative Action, it may be claimed that these ruptures of communication are moral in nature. They occur if an actor's concept of justice does not implicate the justification or the resignation of a validity claim in the given situation (i.e., in relation to her given partner). Thus, the dogmatic interruption of communicative action may be traced back to the narrowness of an actor's concept of justice. Therefore, it may be corrected by changing the actor's concept of justice.

practical ideas of Marx and Freud leads to the unfortunate illusion that Habermas tries to solve the problems of praxis and theory in the same time (1978: 96).

${ }^{5}$ In his book On the Logic of Social Sciences, Habermas formulates a similar idea opposing Gadamer's position. There he argues that one's prejudice-structure may be critically evaluated according to the quality of the processes of its formation (1989)

${ }^{6}$ On the pre-conventional level the concept of justice is either based on the complementarity of order and obedience, or the symmetry of compensation, the social perspective is egocentric and the interactions are motivated either by the authority or the self-interest. On the conventional level, the concept of justice can be characterized as a conformity to roles or system of norms, the social perspective is based on the primary group or the whole group, and accordingly the interactions are governed by the roles or the norms. On the postconventional level the concept of justice is either based on general or procedural principles, the other is seen as a "goal in itself", and the interactions take the form of undistorted discourses (Habermas 1990: 166-167). 
According to Kohlberg, moral development is a unilinear, cognitive learning process. This means that in the course of development, the individual has to gradually pass through all levels step by step. The transition to a higher level of moral development is motivated by frequent experience of the inadequacy of one's concept of justice. The transition itself is realized in the series of moral discourses (Kohlberg 1981). So the changing of an actor's concept of justice (the coordination of action coordination) may be described within these frames by characterizing these discourses.

In situations where the coordination of action coordination becomes necessary, it is not one's concept of justice in general but its narrowness that is responsible for the interruption. So this narrowness has to be altered, and the circle of people perceived as recognized communication partners (to whom the actor justifies or resigns her validity claims) has to be extended. Hence, in order to coordinate action coordination, the actor shall shift to a concept of a higher level of moral development. However, this level is not arbitrary; it has to be the proximate level because of the gradual nature of moral development. Furthermore, the shifting of a concept of justice, as any other mechanism of meaning formulation, is not a monological act but an interaction. This interaction may not take any shape; it has to be in accordance with the problematic actor's concept of justice because this concept determines the maximal rationality of her action coordination. It may be concluded that the coordination mechanism of action coordination is an attempt to shift the actor's problematic concept of justice to a higher level of moral development in the frames of an interaction according to her actual concept of justice. By repeating the original communicative action within the frames of a new, more general concept of justice, the cause of the former interruption may be eliminated, as the former unwillingness to either justify or resign a validity claim will presumably lose its ground in the new moral order.

To clarify the concept, let us review an example. Habermas describes the situation wherein construction workers discuss the details of their midmorning snack and there is a debate between an older worker and a newcomer concerning the person who should bring the beers (Habermas 1987: 121). My example of coordinating action coordination is a variation of this scene. Let us suppose that the older worker and the newcomer not only disagree about who should bring the beer but in addition to this, their concepts of justice differ in a way that their action coordination is endangered. The newcomer is on the second level of moral development, which means that he thinks he is obliged to justify his validity claims only if it is in his best interest. In the present situation, he sees no reason why it would serve his interest if he explained to the older person his reason to refuse bringing beer, so he is simply rejecting the elder's speech act without justifying the rejection, causing the interruption of communicative action. The older worker is on the third level of moral development, thinking that the roles define to whom one is obliged to justify his validity claims. So he tries to handle the situation by communicative means. To do so, he first has to establish the moral basis required for action coordination by attempting to change the newcomer's concept of justice within a discourse according to the newcomer's concept of justice. This means that the elder should prove to the newcomer that it is in his best interest to apply the symmetry of compensation to the more general level of roles (he may argue that it is worth more to compensate between roles than concrete persons, as it is a more stable, economic system). If the elder succeeds and the newcomer shifts to third level of moral development, the interrupted action coordination may be restarted (the newcomer now perceives the elder as a representative of a role to whom he is obliged to justify his validity claims) without the danger of being interrupted again. 


\section{The paradox of coordinating action coordination}

In the conclusion of the previous section I described the coordination of action coordination as an attempt to shift to a more general concept of justice by a moral debate according to the original, narrow concept of justice. In my opinion this conclusion leads to a paradox in a short way. The paradox is caused by the double role played by the concepts of justice in moral debates, which has not been taken seriously enough either by Kohlberg or by Habermas. Concepts of justice underlie every action coordination process by defining the moral perspectives of the actors. This causes a certain difficulty in case of debates on the concepts themselves. Within these debates, the concept of justice appears on two levels: on the formal level of the frame of the action coordination (it defines the moral basis of the form of the debate) and on the substantive level of the communication (it is the topic of the debate). So whenever an attempt is made to change the concept of justice, a paradoxical situation is generated.

The action coordination process that aims to shift the underlying concept of justice to the higher level may never completely succeed because its actual, narrower underlying concept of justice inevitably leaves its mark on the new concept. Accordingly, within the frames of the purely cognitive-linguistic model, only an apparent moral transition may be grasped. To explain this statement the above mentioned features of meaning have to be evoked: knowing a meaning includes in addition to the knowledge of the rule of its use, the knowledge of its justification as well. Furthermore, the knowledge of justification depends on the original process of acquisition: the rationality of the original acquisitive action coordination determines the rationality of the justification (a meaning acquired in a distorted process cannot be rationally justified). Therefore a concept of justice that is acquired in action coordination according to a narrower concept of justice than itself can be justified only according to that narrower concept. However this implicates a paradoxical situation: the form of justification contradicts the justified proposition. In this sense if a speech act is expressed in order to justify a concept of justice acquired in action coordination according to a narrower concept of justice, a "performative contradiction"7 occurs: the way the speech act is expressed (in accordance with the narrow concept of justice) contradicts the expressed propositional content (the broader concept of justice).

The above described example may clarify this conclusion. In case of the newcomer and elder workers who are on the second and third moral level of moral development the problem takes the following shape. The elder persuades the newcomer in action coordination according to the second level (by saying that it is worth to shift) to accept the order of roles. So the newcomer acquires a concept of justice according to the third level of moral development, but he can justify it only according to the second level (by arguing that it is better worth it). This means that the justifying speech act implicates a performative contradiction: by saying that it is worth better to compensate between roles than particular individuals, two contradicting concepts of justice is expressed. The form of the argument is based on the egocentric perspective while the justified proposition concerns the role based perspective. As a matter of fact this justification attests that it is still the second level of moral development that determines the newcomer's moral perspective not the third, as it implicates that in case it is not worth it anymore the role based concept loses its validity.

It is important to emphasize that the conventional concept of justice held for pre-conventional reasons does not simply express a "variant of conventional morality". Instead, as it is grounded on a lower level of moral development, actually it expresses a pre-conventional

\footnotetext{
7 The notion has been elaborated by Apel and Habermas, it occurs when a "speech act $\mathrm{k}(\mathrm{p})$ rests on noncontingent presuppositions whose propositional content contradicts the asserted proposition p" (Habermas 1990: 80)
} 
concept of justice. At the end, it is the reason used in the moral debates that matters: unlike in case of the truth based or aesthetic meanings, in case of moral issues, the way of arguing itself implies a concept of justice. This creates the chance of a contradiction between the logic of argumentation and the expressed concept of justice, which occurs between actors characterized by diverging level of moral development.

In my opinion, from this paradox follows a need for revising Habermas' theory. ${ }^{8}$ Since the transition between concepts of justice can not be grasped within its frames, its completion becomes necessary. In order to find out the direction of the completion, the nature of the paradox has to be further clarified. The paradox is basically caused by the limitation of the circle of possible meaning-formation processes. In Habermas' theory meanings are born and renewed in interactions motivated by the need to solve a dissent in social action situations. More precisely it could be said that he focuses only on these meanings and these meaningformulation processes. However these processes have philosophically elaborated alternatives and some of these alternatives may be fruitfully used in order to resolve the paradox. The wanted alternative meaning-formulation process is required to have two important characteristics: first it has to express a mutually accepted equivalent of a high level concept of justice (that may serve as a possible basis for a linguistic formulation of the new concept of justice), secondly it has to be non-linguistic (to avoid the paradox). ${ }^{9}$ With other words, the wanted alternative is a moral meaning originating from a source that is different from cognitive-intentional justice. This is the point where the postmodern ethics could be connected to the cognitive theory of justice. In his phenomenological writings Levinas describes a meaning-formulation process that seems to satisfy these conditions. So in the following section his relevant ideas will be shortly introduced serving as a potential solution to the paradox.

\section{The Face of the Other and elementary ethics}

In his most important philosophical works Levinas aims to describe a special experience, the birth of a set of meanings, namely our elementary ethical meanings. ${ }^{10}$ In Totality and Infinity he approaches the problem by identifying two complementary sources of meaning, the domain of "the Same" and the domain of "the Other". The Same (or "the Being") has been the main object of philosophical investigation from the ancient Greek to Heidegger, and

\footnotetext{
8 Crossley also argues in many articles that the Habermasian theory needs further grounding by phenomenologies focusing on the bodily and affective phenomena. He argues that The Theory of Communicative Action lacks a theory of affections and a theory of the body, which parts could be elaborated according to the ideas of Merleau-Ponty (Crossley 1996, 1998). In the following section I also lean on an author, whose ideas are deeply connected with the late phenomenology of Merleau-Ponty.

${ }^{9}$ In another context Habermas discusses the problem of the pre-linguistic basis of communicative action. He leans on Durkheim's ideas on the non-verbal ritual practices constituting the sacred roots of morality. In these rites the individual experiences the society itself that is they become a subject of a pre-linguistic meaningformation process expressing a moral consensus (Habermas 1987: 52-53). However, Habermas discusses these ideas in a historical perspective, in order to identify the evolutionary step preceding the shift to linguistic foundation of moral consensus described by Mead. This is the reason why Durkheim's ideas can not be used to our purpose, namely that they represent a historically exceeded stage (the ritual practices of the tribes).

${ }^{10}$ Levianas is often criticized - similarly to other post-structuralist French authors - that his writings are lacking clear argumentation, obscure and therefore unscientific. I think that this criticism misses the point. Levinas' purpose is to give a description of a rare, pre-intentional moral experience. That can be done - because of the pre-intentional nature of the experience - only in a metaphorical language, which is often closer to poetry than to strict philosophical argumentation. However, this does not mean of course that it is lacking any logical structure. In this article my aim is not to critically evaluate Levinas' thoughts, but to use them as a description of a rare moral experience, which helps me to solve the Habermasian paradox.
} 
accordingly ontology has been the first philosophy. Levinas' goal is to analyze the alternative source of meaning, the Other, and to establish the frames of a new phenomenology whose main concern is not the world, but the Other, and whose starting point is not ontology but ethics.

In Totality and Infinity Levinas reconstructs two different kinds of attachment to the world, the enjoyment ("living from...") and the economy (possession, habitation and labor). Our original attachment to the world is pre-intentional: we live from it, that is, we are enjoying the elements of life (the food, the warm weather etc.). This attachment is completed by the intentional economy that is motivated by the urge to gain control over the enjoyable elements by producing them. Enjoyment and labor share the same feature of expressing the mastery of subject over the elements of life. Even if the subject depends on the elements of life as they potentially suffer from their absence, she is master to them as she gives sense to the elements by placing them into her meaning-structure. The identification of this feature enables Levinas to introduce the alternative of the elements of life. He describes a special experience that refuses to be contained, that is, to be placed in a meaning-structure. The source of this experience is the Face of the Other.

The Face resists any attempt to be identified, as it identifies itself, overwrites the meanings tried to be attached to it. ${ }^{11}$ In this sense the Face expresses a meaning from the moment it is perceived as a Face. This meaning is a warning that signifies the limits of one's power, expressing that it can not be extended on the Other the same way as on the elements of life. ${ }^{12}$ It is an imperative that raises an unavoidable decision: the meaning expressed in the experience of the Face may be neglected or may be taken seriously. According to Levinas this decision is the root of every ethics as the choosing of the recognition of the Other implicates an absolute responsibility, an imperative of turning to the other. ${ }^{13}$ This responsibility effects the subject's attachment to the elements of life as well. The two earlier options - instant consumption or accumulation - are competed by a third option, namely the sharing of the elements of life (in literal sense and in the sense of sharing the meanings). In this sense the elementary ethics provides a concept different from the ethics of justice. While justice - since Kant's categorical imperative - is organized around the principle of universality, elementary responsibility is based on particularity. It expresses a devotion to some particular other, which devotion includes even self-sacrifice if necessary.

At this point it is a central question under what circumstances the Face may be perceived and how this process may be described. Levinas examines these questions in detail in his second major book Otherwise than Being or beyond Essence (1998). Unlike in his first book, here he plays down the discussion of the relation of the Other and the elements of life. He focuses instead on the description of the constitution of elementary responsibility. Accordingly here his main distinction refers not to "the Same and the Other", but to the two aspects of language use, "the said and the saying". ${ }^{14}$ The said expresses the Being, and the saying expresses what is beyond this domain. In this sense the saying is the source of different meanings, which are expressed in the act of saying itself. The saying unlike the said can not be characterized as an emission of signs. Instead, in the saying the subjects expose, denude themselves to the Other. However, the exposure is not an action of the subject as actions implicate interests, that is,

\footnotetext{
${ }^{11}$ As Levinas emphasizes it, the Face is not a phenomenon but an enigma (Peperzak 1998: 116).

${ }^{12}$ Levinas uses the word "murder" to express the weight of the rejection of the experience of the Face: to treat the Other as an element of life is to kill her, as killing is only possible if the Other is treated as an object (Levinas: 1969: 232-233).

${ }^{13}$ This responsibility has been called by some philosophers - according to the sense Merleau-Ponty used the expression "wild" - "wild responsibility" (Tengelyi 2004: 123).

14 With this step Levinas gives a completely new sense to the expression "phenomenological reduction", he means by it the "epoche of the said" (that leads to the analysis of the saying). For a detailed analysis of the distinction see Waldenfels' essay, "Levinas on the Saying and the Said" (2005)
} 
they concern the domain of Being. The exposure of the subject is the result of her passivity, as passivity allows the absolute offering of oneself to the Other, the "substitution", the "pledge of taking the pain of the Other". In this sense only passivity allows pure proximity, wherein the experience of the Face is possible and the elementary responsibility may be born. ${ }^{15}$

Accordingly elementary responsibility is not the result of a process of intentional meaningformation (either monological or interactive), but the result of passive, unintentional meaning-expression, the result of the proximity of two subjects. The responsibility expressed in proximity is absolute (that is, it implicates the complete subordination of oneself for the Other). Therefore it has to be limited in the very moment when a third subject appears. The appearance of "the third" leads from the elementary ethics to the domain of society and politics. The limitation of the absolute responsibility takes the shape of cognitive concepts of justice. Accordingly every elaborated theory of justice (political or moral philosophy) can be treated as the limited, cognitive explication of the elementary ethics.

The inevitable limitation of elementary responsibility explains why the experience of the Face is so rare in everyday life. ${ }^{16}$ It occurs only in those unique situations, wherein subjects expose themselves to each other in the proximity of their passivity. Levinas' examples are different intimate relations such as the mother and the child or two lovers. However, it is important to emphasize that he uses the expression proximity not only in metaphorical, but literal sense as well. He refers to caress or embrace as the par excellence characteristics of proximity, that is, he considers the expression of elementary responsibility depending on circumstances of the subject's bodily connection (Levinas 1998: 80, 82, 90). In this sense caress and embrace are tools of slashing the drape of the socially determined order of bodies, that is, a chance of conjuring the elementary responsibility in the place of the cognitive concepts of justice. ${ }^{17}$

\section{Coordinating action coordination and the Face of the Other}

After outlining the most important ideas of Levinas, we can return to the original line of thought and try to answer the question how the transition between different concepts of justice is possible. Although Levinas and Habermas are two major figures in continental philosophy, only a few attempts have been made to combine their ideas. ${ }^{18}$ Probably the difference of their theoretical goals and their terminology is responsible for this lack. To

\footnotetext{
${ }^{15}$ In passivity the psyche of the subject is expressed, more precisely it is born in this exposition. Accordingly Bergo describes the Otherwise than Being as a "psyche-analysis" emphasizing the parallel of the Freudian and Levinasian ideas (2005:.122).

${ }^{16}$ Even if in everyday situations it is usually a cognitive concept of justice that determines the relation of two subjects, it is crucial to return to the experience of elementary responsibility from time to time, because without it, the former becomes empty as well. Accordingly there is a continuous oscillation between the two levels (Simmons 1999: 84).

17 The evoking of elementary responsibility seems even more difficult if we think about Foucault's analysis, which inform us about the penetration of the power/knowledge into the domain of the elementary, intimate relations (1990).

${ }^{18}$ However, in the recent past more and more effort has been made to fill this gap. In the first place the works of Hendley have to be mentioned, who has made many important contributions to synthetize the Habermasian and Levinasian ideas from a moral philosophical perspective. He argues that as Habermas and Levinas grasp the two sides of the same coin (the problem of moral significance of language), their ideas complete each other in many ways (Hendley 1996, 2000). In addition to Hendley's work a few other contributions might be mentioned: Vetlesen elaborates a comparison of the two moral philosophical concepts (1997), Smith analyses the role of the Levinasian ideas played in the "philosophical discourse of modernity" (2008).
} 
overcome these difficulties and to prepare the fusion of the two concepts, first their different and similar aspects have to be clearly formulated.

Levinas is interested in the foundation of an ethical phenomenology, while Habermas' main concern is a critical social theory grounded on the level of formal pragmatics. In these different theoretical settings they both touch upon the problem of the concepts of justice. However they approach it from different directions, with different purposes in mind: Levinas is interested in the fundamental level underlying the concepts of justice, while Habermas is interested in the role of the concepts of justice played in speech acts. In Habermas' theory the concepts of justice are the final grounds of speech acts as they determine the order of justification (that is, in what situations/relations is a subject ready to justify her validity claims), which means they serve as explanans. For Levinas the concepts of justice are not the final grounds, but the cognitive limitations of the elementary ethical meaning, the absolute responsibility, which means that they are only derived meanings serving as explanandum.

In this sense the two theories are complementary: Levinas discusses the origins of those concepts of justice that Habermas leans on, and conversely Habermas elaborates how the concepts of justice contribute directly to the order of speech acts (and indirectly to the reproduction of the lifeworld) that Levinas ignores. ${ }^{19}$ The two complementary theories are based on two different models of meaning-formation. For Habermas meaning-formation is an intentional linguistic interaction. For Levinas it is imperative to escape the frames of intentionality as it prevents the perception of the Face in its pure form, independent from socially influenced meanings. ${ }^{20}$ So Levinas describes a pre-intentional alternative of meaning-formation, which is not based on activity (interaction), but on the passivity of subjects and the proximity constituted by this passivity.

I concluded the section of the paradox of coordinating action coordination in the hope that a pre-intentional process producing moral meanings of alternative source but equivalent capacity may solve the paradox. Now that the introduction of such a mechanism and the preparations of the synthesis have been done, the details of the solution may be elaborated. As described above, the paradox raises at the point where an attempt is made to describe the action coordination process within which a higher level concept of justice is formulated. This meaning-formation process is necessarily in accordance with the original, narrower concept of justice, and because of this the new, broader concept can be justified only according to the narrow one, which causes a performative contradiction. To evade this dead-end the phase of a pre-intentional meaning-formation process (expressing a concept of justice according to a high level of moral development) has to be built into the process of transition.

Interpreting this problem in the Levinasian frames may offer a solution. If the actors trying to coordinate their action coordination evoke the circumstances wherein the elementary responsibility may be expressed (that is, if they enter into proximity), a high level, consensual morality becomes accessible. The elementary responsibility is an "original impression" ("Urimpression"), and as such, if conjured, it overwrites the validity of any other cognitive concepts of justice. However, as elementary responsibility is absolute, it needs to be limited.

\footnotetext{
${ }^{19}$ Hendley arrives to a similar conclusion on a different way (2004). His starting point is Taylor's critique of the discourse ethics, because of its incapability to answer the question "why to be good?" (1991). Hendley treats Levinas' ideas as answers to this question: "The position I have been arguing for is (...) implying only that a fully intelligible appropriation of the procedural demands of communicative action would be impossible for someone not capable of this [Levinasian] form of sensibility" (Hendley 2004: 169). In accordance with Hendley's point of view it may be added, that the complementarity is mutual, as Habermas answers questions in return that Levinas ignores.

${ }^{20}$ In order to explain the origins of morality Levinas had to find an empirical source of ethical meanings, which is independent from the intentional, socially constructed ethical meanings. And it was exactly the introduction of an alternative, pre-intentional process of meaning-formation that allowed Levinas to reconstruct the frames of a universal, "original impression", "Urimpression" in the Husserlian terminology (MacAvoy 2005: 109-118).
} 
Therefore the elementary responsibility implicates its transformation into a cognitive concept of justice. Furthermore elementary responsibility is equivalent of the concept of justice according to the highest level of moral development, and as such, it provides the basis for the most rational action coordination process, the undistorted communicative action. ${ }^{21}$ To conclude, it may be useful to summarize these features of elementary responsibility: firstly, expressed in proximity, as an alternative concept of justice it may establish the frames of a process of action coordination; secondly, because of its absoluteness, elementary responsibility includes the urge to be transformed into a cognitive concept of justice; thirdly, as it is expressed through pre-intentional processes and as it expresses a concept of justice according to the highest level of moral development, it is not encumbered with the paradox of the cognitive-linguistic model.

Therefore, by building the phase of evoking the elementary responsibility into the description of the coordination of action coordination, its paradox may be dissolved and an expanded model of action coordination may be outlined.

Table 3: Expanded sequence of speech acts

\begin{tabular}{|c|c|c|c|}
\hline rounds/ speakers & speaker "A" & \multicolumn{2}{|l|}{ speaker "B" } \\
\hline \multirow{2}{*}{$\begin{array}{l}\text { 1-3. rounds: the } \\
\text { same as in Table } \\
2\end{array}$} & $\ldots$ & & \\
\hline & $\begin{array}{l}\text { or refuses "q" } \\
\text { without justifying } \\
\text { "p" (i.e. } \\
\text { formulating } \\
\text { speech act "r") } \rightarrow \\
\text { unwilling } \\
\text { interruption of } \\
\text { communicative } \\
\text { action }\end{array}$ & & \\
\hline \multirow[t]{4}{*}{ 4. round } & & \multicolumn{2}{|c|}{ either resigns from communication } \\
\hline & & \multicolumn{2}{|c|}{$\begin{array}{l}\text { or changes to open or hidden violence } \rightarrow \\
\text { willing interruption of communicative } \\
\text { action } \rightarrow \text { unsuccessful ending of } \\
\text { communication }\end{array}$} \\
\hline & & \multirow[t]{2}{*}{$\begin{array}{l}\text { or makes an } \\
\text { attempt to } \\
\text { coordinate action } \\
\text { coordination }\end{array}$} & $\begin{array}{l}\text { either uses only } \\
\text { cognitive } \\
\text { argumentation } \rightarrow \\
\text { paradox shifting to } \\
\text { broader concept of } \\
\text { justice }\end{array}$ \\
\hline & & & $\begin{array}{l}\text { or evokes elementary } \\
\text { responsibility } \rightarrow \\
\text { successful shifting to } \\
\text { broader concept of } \\
\text { justice } \rightarrow \text { returning } \\
\text { to communicative } \\
\text { action }\end{array}$ \\
\hline
\end{tabular}

Table 3 shows this expanded model of action coordination that includes the variations of coordinating action coordination as well. If a situation occurs in which an actor faces unwilling (dogmatic) interruption of communicative action, she has four options: either she treats the situation as hopeless and resigns from communication; or she changes to open or

21 The elementary responsibility implicates a maximal willingness to open oneself to the Other, which is a commitment to revalidate one's meaning-structure in the light of the Other's. As László Tengelyi argues the Levinasian elementary responsibility is in close connection with the Kantian categorical imperative as they are different sources of morality but none can be imagined without supposing the other (2004: 126). Furthermore Levin characterizes Levinas" concept as the "embodiment of categorical imperative" (2001). Hendley in his above mentioned articles shows the same thing in case of the undistorted debate of discourse ethics, which is not surprising as it is the reformulation of the moral law within the frames of formal pragmatics (2004: 159-160). 
hidden violence; or she tries to establish a broader moral order within which the communication may be continued in a purely cognitive manner resulting in a paradox; or she attempts to establish the broader moral order in an action coordination whose moral basis is none other than the elementary responsibility resulting in a potential success. In this model the Levinasian and Habermasian elements constitute a coherent unity. The pre-intentional meaning-formation is needed to broaden the narrow scope of a theory working solely with a concept of cognitive meaning-formation. Conversely, the cognitive model of moral development is needed to explain the potential translations of the elementary responsibility into different concepts of justice. In this sense only the complementarity of the two levels of meaning-formation explains fully the problem of coordinating action coordination. ${ }^{22}$

At this point it is useful to return one last time to the example of the older worker (third level of moral development) and the newcomer (second level of moral development). Their dissent may be solved if in the first step the elder worker - by a friendly gesture (for example a friendly tapping on the newcomer's shoulder) - tries to evoke proximity, and wake the elementary responsibility. If he succeeds, then the circumstances of a quality debate are ensured, enabling him to argue that it is not the interest, but the responsibility toward the other that justifies the recognition of roles. In this way the newcomer acquires the new, broader concept of justice in a dialogue whose concept of justice is broad; and by applying the new concept of justice, the original debate may be recast without the chance of interruption, that is, the action coordination becomes coordinated.

This conclusion is the answer to our starting question, how the elementary ethics and the cognitive concepts of justice may be connected? Their synthesis provides an opportunity to give a more complete description of action coordination mechanisms, and to expand the frames of the phenomenological concept of The Theory of Communicative Action into a direction fitting to late modern constellation.

\section{Concluding remarks}

In the concluding section, I would like to briefly indicate the stakes of the above line of thought and illuminate some of its broader consequences. Communicative action is the central notion of Habermas's theory, so its modification affects his whole system of thought. The relevance of coordinating action coordination for social integration has to be indicated. Habermas starts Between Facts and Norms with the observation that the late modern societies are burdened with the tendency of gradual pluralization of lifeworlds, which endangers the social integration of society. Therefore, he concludes that the need for legal social integration grows as well (Habermas 1996: 26-27). I think that this observation is hardly disputable, unlike the conclusion, which might have several alternatives. The coordination of action coordination is such an alternative, as it is also an answer to the challenge of the lifeworld pluralization, however not a legal theoretic but an action theoretic one. Accordingly, the integration problems being implied by lifeworld pluralization - common in multicultural societies - can be solved not just by legal social integration but by the coordination of action coordination as well.

Secondly, it has to be emphasized that the coordination of action coordination has consequences not just for social integration but for socialization as well. Communicative

\footnotetext{
22 Obviously at this point there are many empirical and theoretical questions, which require further analysis. As the elementary responsibility is the result of passivity, instead of intentional preconditions, those contextual factors need to be identified, which may ensure its emergence. Also those mechanisms need to be analyzed in further researches, which are responsible for translating the elementary experiences of responsibility into concepts of justice.
} 
action is the complementary and, at the same time, reproduction mechanism of the lifeworld. It becomes necessary if the lifeworld does not ensure the horizon of mutual meanings. Then, it solves the problem in the particular action situation and, at the same time, reproduces the lifeworld by creating a new horizon. The connection between coordinating action coordination and action coordination is analogous with the connection between action coordination and the lifeworld. Coordinating action coordination becomes necessary if action coordination is not functioning, that is, if it cannot ensure the recreation of a new horizon of meaning. Then, the coordination of action coordination solves the problem in the particular situation and "reproduces" a new habit of action coordination at the same time by practicing it. As the obstruction of action coordination becomes a more and more frequent problem in the individualized, differentiated late modernity, the questions of coordinating action coordination become more and more important for a late modern theory of socialization. Only such a theory is capable of highlighting potential solutions for the new challenges arising because of the dissolution of a mutual lifeworld.

Thirdly, the consequences concerning Habermas's normative basis have to be mentioned. The original normative basis in The Theory of Communicative Action is the undistorted series of speech acts (introduced in Table 1). However, this highly rational type of action coordination is itself a result of a socialization process, including a moral development that leans on the Levinasian proximity. Therefore, the pragmatic normative basis is indirectly dependent on the proximity, which means that lack of proximity could be rightfully criticized in the relevant situations. In this sense, Habermas's formal pragmatic normative basis can be complemented on the level of socialization theory with the concept of proximity.

Finally, the theoretical consequence has to be mentioned, namely the one that concerns the historical conclusions and the diagnosis of time of The Theory of Communicative Action. As it is well known, Habermas describes three major trends of social evolution: the rationalization of lifeworld, the differentiation of the systems, and the uncoupling of the lifeworld and system. Furthermore, as a diagnosis of time, he describes the colonization of the lifeworld by the system introducing it as a pathological tendency. In the light of what has been told about the coordination of action coordination, these ideas may be revised as well. As the proximity is an essential prerequisite of coordinating action coordination, which is the prerequisite of the rationalization of the lifeworld, it becomes a crucial question regarding how proximity can be historically featured and how its historical dynamism affects the original Habermasian diagnosis of time. ${ }^{23}$ Even if these questions require further research and may only be mentioned here, it is important to emphasize their relevance, as they are crucial elements of the diagnosis of our own times.

\section{References}

Beck, U. (1992) Risk Society: Towards a New Modernity. trans. Ritter, M. London: Sage.

Bergo, B. (2005) 'What Is Levinas Doing? Phenomenology and the Rhetoric of an Ethical Un-Conscious', Philosophy and Rhetoric 38(2): 122-144. CrossRef

Crossley, N. (1996) 'Corporeality and communicative action: embodying the renewal of critical theory', Body and Society 3(1): 17-46. CrossRef

\footnotetext{
${ }^{23}$ The works analyzing the historical transformation of intimacy - such as Luhmann's Love as passion: the codification of intimacy or Foucault's History of sexuality or Giddens' Transformation of intimacy - may provide insight concerning the changes of proximity. In the future these results should be connected to the original Habermasian diagnosis.
} 
Crossley, N. (1996) 'Emotion and communicative action: Habermas, linguistic philosophy and existentialism', in Bendelow-G. Williams, S (ed.): Emotions in Social Life. London: Routledge.

Foucault, M. (1990) The history of sexuality. trans. Hurley, R. New York: Vintage Books

Honneth, A. (2007) 'The Other of Justice: Habermas and the Ethical Challenge of Postmodernism', in Disrespect - The normative Foundations of Critical Theory, Cambridge: Polity Press.

Habermas, J. (1971) Knowledge and Human Interests. trans. Shapiro, J. Boston: Beacon. Press.

Habermas, J. (1984) The Theory of Communicative Action. Volume 1, trans. McCarthy, Th. Boston: Beacon Press.

Habermas, J. (1987) The Theory of Communicative Action, Volume 2, trans. McCarthy, Th., Boston: Beacon Press.

Habermas, J. (1989) On the Logic of Social Sciences, transl. Weber, S. N., Stark, J. A. Cambridge, UK: MIT Press.

Habermas, J. (1990) Moral Consciousness and Communicative Action. In Moral Consciousness and Communicative Action, trans. Lenhardt, Ch. and Weber, S. N., Cambridge: Polity Press.

Habermas, J. (1990) 'Discourse Ethics: Notes on a Program of Philosophical Justification', in Moral Consciousness and Communicative Action, trans. Lenhardt, Ch. and Weber, S. N., Cambridge: Polity Press.

Habermas, J. (1996) Between Facts and Norms: Contributions to a Discourse Theory of Law and Democracy, trans. Rehg, W. Cambridge: Polity Press.

Habermas, J. (1998) Reflections on Communicative Pathology. In On the Pragmatics of Social Interaction, trans. Fultner, B. Cambridge: MIT Press.

Hendley, S. (1996) 'From Communicative Action to the Face of the Other: Habermas and Levinas on the Foundations of Moral Theory', Philosophy Today 40(4): 504-530. CrossRef

Hendley, S. (2000) From Communicative Action to the Face of the Other: Levinas and Habermas on Language, Obligation, and Community. Lanham: Lexington Books.

Hendley, S. (2004) 'Speech and sensibility: Levinas and Habermas on the constitution of the moral point of view', Continental Philosophy Review 37(2): 153-173 CrossRef

Kohlberg, L. (1981) The Philosophy of Moral Development: Moral Stages and the Idea of Justice. San Francisco: Harper \& Row.

Lash, S. (1999) Another Modernity, A Different Rationality, Oxford: Blackwell.

Levin, D. M. (2001) 'The embodiment of the categorical imperative: Kafka, Foucault, Benjamin, Adorno and Levinas' Philosophy \& Social Criticism 27(4): 1-20. CrossRef

Lévinas, E. (1969) Totality and Infinity, trans. Lingis, A. Pittsburg: Duquesne University Press.

Lévinas, E. (1998) Otherwise than Being or beyond Essence. trans. Lingis, A. Pittsburgh: Duquesne University Press.

MacAvoy, L. (2005) The Other Side of Intentionality. In Nelson, E., Kapust, A., Still, K. (eds.) Addressing Levinas, pp. 109-118. Evanston: Northwestern University Press.

McCarthy, T. (1978) The Critical Theory of Jürgen Habermas. London: Hutchinson.

Peperzak, A. (1998) 'Levinas' method', Research in Phenomenology 28(1): 110-125. CrossRef

Sik, D. (2012) A modernizáció ingája. (The pendulum of modernization) Budapest: ELTE-Eötvös Kiadó.

Simmons, P. W. (1999) 'The Third: Levinas' theoretical move from an-archical ethics to the realm of justice and politics' Philosophy and Social Criticism 25(6) 83-104. 
Smith, N. H. (2008) 'Levinas, Habermas and modernity', Philosophy and Social Criticism 34(6): 643-664. CrossRef

Taylor, C. (1991) 'Language and Society', in Honneth, A., Joas, H. (eds.): Communicative Action - Essays on Jürgen Habermas's The Theory of Communicative Action, Cambridge: MIT Press.

Tengelyi, L. (2004) The Wild Region in Life-History, trans. Kallay, G. Evanston: Northwestern University Press.

Vetlesen, J. (1997) 'Worlds apart? Habermas and Levinas', Philosophy and Social Criticism 23(1): 1-20. CrossRef

Waldenfels, B. (2005) 'Levinas on the Saying and the Said', in Nelson, E., Kapust, A., Still, K. (eds.) Addressing Levinas, Evanston: Northwestern University Press. 